Pacific Journal of Mathematics

NON NEWMAN ALGEBRAS GENERATED BY OPERATORS 


\title{
VON NEUMANN ALGEBRAS GENERATED BY OPERATORS SIMILAR TO NORMAL OPERATORS
}

\author{
W. R. WOGEN
}

\begin{abstract}
A normal operator generates an abelian von Neðmann algebra. However, an operator which is similar to a normal operator may generate a von Neumann algebra which is not even type I. In fact, it is shown that if $\mathscr{A}$ is a von Neumann algebra on a separable Hilbert space and $\mathscr{A}$ has no type II finite summand, then $\mathscr{A}$ has a generator which is similar to a self-adjoint and $\mathscr{A}$ has a generator which is similar to a unitary. The restriction that $\mathscr{A}$ have no type II finite summand can be removed provided that it is assumed that every type II finite von Neumann algebra has a single generator.
\end{abstract}

Let $\mathscr{\mathscr { C }}$ be a separable Hilbert space and let $\mathscr{A}$ be a von Neumann algebra on $\mathscr{H}$. $\mathscr{A}^{\prime}$ denotes the commutant of $\mathscr{A}$. For $n \geqq 2$, let $M_{n}(\mathscr{A})$ denote the von Neumann algebra of $n \times n$ matrices with entries in $\mathscr{A}$. If $T$ is a bounded operator, the $\mathscr{R}(T)$ is the von Neumann algebra generated by $T$.

We begin with some lemmas.

Lemma 1. Let $\mathscr{A}=\mathscr{R}(C)$ and suppose $n \geqq 3$. Let $\left\{\lambda_{k}\right\}_{k=1}^{n}$ and $\left\{a_{k}\right\}_{k=1}^{n-1}$ be sequences of complex numbers such that the $\lambda_{k}$ are distinct, each $a_{k} \neq 0$, and $\left\|\left(\lambda_{1}-\lambda_{2}\right) C\right\| \leqq\left|a_{1} a_{2}\right|$. Define $A=\left(A_{i, j}\right)_{i, j=1}^{n} \in M_{n}(\mathscr{A})$ by $A_{k, k}=\lambda_{k} I, A_{k+1, k}=a_{k} I, A_{3,1}=C$, and $A_{i, j}=0$ otherwise. Define $B=\left(B_{i, j}\right)_{i, j=1}^{n} \in M_{n}(\mathscr{A})$ by $B_{k, k}=\lambda_{k} I$ and $B_{i, j}=0$ if $i \neq j$. Then $A$ and $B$ are similar, and $\mathscr{R}(A)=M_{n}(\mathscr{A})$.

Proof. It follows from [11, Lemma 1] that $\mathscr{R}(A)=M_{n}(\mathscr{A})$. To show that $A$ and $B$ are similar we need only that the $\lambda_{k}$ are distinct. We must find an invertible operator $S$ such that $A S=S B$. Such an $S$ of the form $S=I+N$, where $N$ is lower triangular and nilpotent, can be computed easily. Merely perform the matrix multiplications and solve for the entries of $S$. We omit the details.

REMARK 1. If the operator $S=I+N$ in Lemma 1 is computed, we see that we can make the entries of $N$ small by choosing $\|C\|$, $\left|a_{1}\right|,\left|a_{2}\right|, \cdots,\left|a_{n-1}\right|$ suitably small. Hence we can suppose that $\|N\|<$ 1/2. Then $\|S \mid=\| I+N \|<3 / 2$ and $\left\|S^{-1}\right\|=\| I-N+N^{2}-\cdots \pm$ $N^{n-1} \|<2$. Note also that by choosing $\|C\|,\left|a_{1}\right|,\left|a_{2}\right|, \cdots,\left|a_{n-1}\right|$ suitably, we can assume that $\|A\| \leqq\|B\|+1$. 
The following is a corollary of Lemma 1.

CoRollary 1. If $\mathscr{A}$ is a properly infinite von Neumann algebra on $\mathscr{H}$, then $\mathscr{A}$ has a generator which is similar to a self-adjoint operator.

Proof. If $\mathscr{A}$ is properly infinite, then it is well-known that $\mathscr{A}$ is *-isomorphic to $M_{3}(\mathscr{A})$. $\mathscr{A}$ has a single generator $C$ by [10]. Construct a generator $A$ of $M_{3}(\mathscr{A})$ as in Lemma 1, with $\lambda_{1}, \lambda_{2}$, and $\lambda_{3}$ real. Then $A$ is similar to self-adjoint operator by Lemma 1 . (Another easy proof of Corollary 1 can be deduced from methods in the proof of Corollary 1 in [1].)

It has been shown that if $\mathscr{A}$ is properly infinite, then $\mathscr{A}$ is generated by three projections [9] and by two idempotents [4]. A related result is

CoRollary 2. If $\mathscr{A}$ is a properly infinite von Neumann algebra on $\mathscr{H}$, then $\mathscr{A}$ is generated by three commuting idempotents.

Proof. If $A$ is the generator of $\mathscr{A}$ constructed in Corollary 1, let $E$ be the (idempotent valued) spectral measure of $A$. Then $E\left(\lambda_{1}\right)$, $E\left(\lambda_{2}\right)$, and $E\left(\lambda_{3}\right)$ are the required commuting idempotents.

Let $\sigma(C)$ denote the spectrum of the operator $C$.

Lemma 2. Let $\mathscr{A}=\mathscr{R}(C)$. Let

$$
A=\left[\begin{array}{cc}
C & 0 \\
\alpha I & \lambda I
\end{array}\right], \quad B=\left[\begin{array}{cc}
C & 0 \\
0 & \lambda I
\end{array}\right],
$$

where $a \neq 0$ and $\lambda \notin \sigma(C)$. Then $A$ is similar to $B$, and $\mathscr{R}(A)=M_{2}(\mathscr{A})$.

Proof. A routine computation shows that

$$
\mathscr{R}(A)^{\prime}=\left\{\left[\begin{array}{cc}
T & 0 \\
0 & T
\end{array}\right]: \quad T \in \mathscr{A}^{\prime}\right\} .
$$

It follows that $\mathscr{R}(A)=\mathscr{R}(A)^{\prime \prime}=M_{2}(\mathscr{A})$. Let

$$
S=\left[\begin{array}{cc}
I & 0 \\
a(C-\lambda I)^{-1} & I
\end{array}\right]
$$

Then $S$ is invertible and $A S=S B$.

LEMmA 3. Let $\left\{A_{k}\right\}_{k=0}^{\infty}$ be a uniformly bounded sequence of operators. Suppose that the $A_{k}$ have pairwise disjoint spectra. Then 


$$
\mathscr{R}\left(\sum_{k=0}^{\infty} \oplus A_{k}\right)=\sum_{k=0}^{\infty} \oplus \mathscr{R}\left(A_{k}\right)
$$

Proof. The proof given here is due essentially to Rosenthal [8, Th. 3]. (See also [3, Lemma].) Let $A=\sum_{k=0}^{\infty} \oplus A_{k}$. Suppose $C=$ $\left(C_{i j}\right)_{i, j=0}^{\infty}$ commutes with $A$. Then

$$
C_{i, j} A_{j}=A_{i} C_{i, j} \text { for all } i, j \text {. }
$$

If $i \neq j$, then $\sigma\left(A_{i}\right)$ and $\sigma\left(A_{j}\right)$ are disjoint, so by a theorem of Rosenblum [7], $C_{i j}=0$. It follows that $\mathscr{R}(A)^{\prime}=\sum_{k=0}^{\infty} \oplus \mathscr{R}\left(A_{k}\right)^{\prime}$, so that $\mathscr{R}(A)=\mathscr{R}(A)^{\prime \prime}=\sum_{k=1}^{\infty} \oplus \mathscr{R}\left(A_{k}\right)$.

THEOREM 1. If $\mathscr{A}$ is a von Neumann algebra on a separable Hilbert space such that $\mathscr{A}$ has no type II finite summand, then $\mathscr{A}$ has a generator which is similar to a self-adjoint operator.

Proof. Write $\mathscr{A}=\sum_{n=0}^{\infty} \oplus \mathscr{A}_{n}$, where $\mathscr{A}_{0}$ is properly infinite and for each $n \geqq 1, \mathscr{A}_{n}$ is an $n$-homogeneous type I summand (see [2]). (Note that some of these summands may be absent.) Let $\left\{I_{n}\right\}_{n=0}^{\infty}$ be a pairwise disjoint sequence of nonempty subintervals of $[0,1]$.

By Corollary 1, we can choose $A_{0}$ and an invertible operator $S_{0}$ such that $\mathscr{R}\left(A_{0}\right)=\mathscr{A}_{0}, S_{0} A_{0} S_{0}^{-1}$ is self-adjoint, and $\sigma\left(A_{0}\right) \subset I_{0}$.

For each $n \geqq 1, \mathscr{A}_{n}$ is ${ }^{*}$-isomorphic to $M_{n}\left(\mathscr{C}_{n}\right)$, where $\mathscr{C}_{n}$ is the center of $\mathscr{A}_{n}$ (see [2]). $\mathscr{C}_{n}$ is abelian, so $\mathscr{C}_{n}$ has a self-adjoint generator by [5]. Let $A_{1}$ be a self-adjoint generator of $\mathscr{A}_{1}=\mathscr{C}_{1}$. By translating and scaling, if necessary, we can assume $\sigma\left(A_{1}\right) \subset I_{1}$. Let $S_{1}$ be the identity in $\mathscr{A}_{1}$.

Let $C$ be a self-adjoint generator of $\mathscr{C}_{2}$ with $\sigma(C)$ properly contained in $I_{2}$. Let $\lambda \in I_{2}$ with $\lambda \notin \sigma(C)$. Let $a \neq 0$ and let

$$
A_{2}=\left[\begin{array}{cc}
C & 0 \\
a I & \lambda I
\end{array}\right]
$$

Then by Lemma 2, $\mathscr{R}\left(A_{2}\right)=\mathscr{A}$ and for some invertible $S_{2}, S_{2} A_{2} S_{2}^{-1}$ is self-adjoint. Also, $\sigma\left(A_{2}\right)=\sigma(C) \cup\{\lambda\} \subset I_{2}$.

For $n \geqq 3$, use Lemma 1 to construct $A_{n}$ and an invertible $S_{n}$ such that $\mathscr{R}\left(A_{n}\right)=\mathscr{A}_{n}, S_{n} A_{n} S_{n}^{-1}$ is self-adjoint, and $\sigma\left(A_{n}\right) \subset I_{n}$. Moreover by Remark 1, we can suppose that the sequences $\left\{A_{n}\right\},\left\{S_{n}\right\}$, and $\left\{S_{n}^{-1}\right\}$ are uniformly bounded.

Let $A=\sum_{n=0}^{\infty} \oplus A_{n}$, and let $S=\sum_{n=0}^{\infty} S_{n}$. Then $A$ and $S$ are bounded operators, $S$ is invertible, and $S A S^{-1}$ is self-adjoint. Finally $\mathscr{R}(A)=\sum_{n=0}^{\infty} \oplus A_{n}$ by Lemma 3 .

It has long been conjectured that every von Neumann algebra on a separable Hilbert space has a single generator. Results in [6] and 
[10] reduce the proof of the conjecture to showing that $(S)$ Every type II finite von Neumann algebra on a separable Hilbert space has single generator. (See [4] for a partial solution to this conjecture.)

THeOREm 2. If $(S)$ is true and $\mathscr{A}$ is a von Neumann algebra on a separable Hilbert space, then $\mathscr{A}$ has a generator which is similar to a self-adjoint operator.

Proof. Write $\mathscr{A}=\mathscr{A}_{1} \oplus \mathscr{A}_{2}$, where $\mathscr{A}_{1}$ has no type II finite summand and $\mathscr{A}_{2}$ is type II finite. By Theorem $1, \mathscr{A}_{1}$ has a generator $A_{1}$ which is similar to a self-adjoint operator. Construct a generator of $\mathscr{A}_{2}$ as follows: Choose a projection $E \in \mathscr{A}_{2}$ such that $\mathscr{A}_{2}$ is spatially *-isomorphic to $M_{4}\left(E \mathscr{A} \mathscr{A}_{2} E\right) . E \mathscr{A}_{2} E$ is type II finite, so $E \mathscr{A}_{2} E$ has a single generator by assumption. Now use Lemma 1 to construct a generator $A_{2}$ of $\mathscr{A}_{2}$ which is similar to a self-adjoint and such that $\sigma\left(A_{1}\right)$ and $\sigma\left(A_{2}\right)$ are disjoint. Then $A_{1} \oplus A_{2}$ is similar to a self-adjoint operator, and $\mathscr{R}\left(A_{1} \oplus A_{2}\right)=\mathscr{A}_{1} \oplus \mathscr{A}_{2}$.

We now indicate briefly how the previous results can be obtained with "similar to a self-adjoint" replaced by "similar to a unitary,"

CoRollary 1'. If $\mathscr{A}$ is a properly infinite von Neumann algebra on $\mathscr{H}$, then $\mathscr{A}$ has a generator which is similar to a unitary operator.

The proof is the proof of Corollary 1 , except that $\lambda_{1}, \lambda_{2}$, and $\lambda_{3}$ must be chosen on the unit circle. (See [1] for another proof.)

THeOREm 1'. If $\mathscr{A}$ is a von Neumann algebra on a separable Hilbert space such that $\mathscr{A}$ has no type II finite summand, then $\mathscr{A}$ has a generator which is similar to a unitary operator.

Proof. Proceed as in the proof of Theorem 1. Write $\mathscr{A}=$ $\sum_{n=0}^{\infty} \oplus \mathscr{A}_{n}$. Use Lemmas 1 and 2 and Corollary $1^{\prime}$ to construct generators $A_{n}$ of the $\mathscr{A}_{n}$ which have pairwise disjoint spectra on the unit circle. Then each $A_{n}$ will be similar to a unitary operator. To handle the summands $\mathscr{A}_{1}$ and $\mathscr{A}_{2}$, we need the following: If $C$ is a self-adjoint generator of $\mathscr{C}$, then $e^{i C}$ is a unitary generator of $\mathscr{C}$ and $\sigma\left(e^{i C}\right)=\left\{e^{i \lambda}: \lambda \in \sigma(C)\right\}$. The rest of the proof is clear.

Finally we have

THEOREM 2'. If $(S)$ is true and $\mathscr{A}$ is a von Neumann algebra on a separable Hilbert space, then $\mathscr{A}$ has a generator which is similar to a unitary operator. 


\section{REFERENCES}

1. H. Behncke, Generators of $W^{*}$-algebras, Tôhoku Math. J., 22 (1970), 541-546.

2. J. Dixmier, les algebres d'operateurs dans l'espace Hilbertien, Gauthier-Villars, Paris, 1969, Deuxieme Edition.

3. R. Douglas and C. Pearcy, Von Neumann algebras with a single generator, Mich. Math. J., 16 (1969), 21-26.

4. R. Douglas and D. Topping, Operators whose squares are zero, Rev. Romaine Math. Pures Appl., 12 (1967), 647-652.

5. J. von Neumann, Zur Algebra der Functional Operatoren und Theorie der Normal Operatoren, Math. Ann., 102 (1929), 370-427.

6. C. Pearcy, $W^{*}$-algebras with a single generator, Proc. Amer. Math. Soc., 13 (1962), 831-832.

7. M. Rosenblum, On the operator equation $B X-X A=Q$, Duke Math. J., 23 (1956), 263-269.

8. P. Rosenthal, Completely reducible operators, Proc. Amer. Math. Soc., 19 (1968), 826-830.

9. T. Saitô, Generators of certain von Neumann algebras, Tôhoku Math. J., 20 (1968), 101-105.

10. W. Wogen, On generators for von Neumann algebras, Bull. Amer. Math. Soc., 75 (1969), 95-99.

11. - On special generators for properly infinite von Neumann algebras, Proc. Amer. Math. Soc., 28 (1971), 107-113.

Received October 23, 1970.

University of North Carolina at Chapel Hill 



\section{PACIFIC JOURNAL OF MATHEMATICS}

\section{EDITORS}

\author{
H. SAMElson \\ Stanford University \\ Stanford, California 94305 \\ C. R. HOBBY \\ University of Washington \\ Seattle, Washington 98105
}

J. DugundjI

Department of Mathematics University of Southern California Los Angeles, California 90007

RICHARD ARENS

University of California

Los Angeles, California 90024

\section{ASSOCIATE EDITORS}
E. F. BECKENBACH
B. H. NeUmanN
F. WOLE
K. YOSHIDA

\section{SUPPORTING INSTITUTIONS}

\author{
UNIVERSITY OF BRITISH COLUMBIA \\ CALIFORNIA INSTITUTE OF TECHNOLOGY \\ UNIVERSITY OF CALIFORNIA \\ MONTANA STATE UNIVERSITY \\ UNIVERSITY OF NEVADA \\ NEW MEXICO STATE UNIVERSITY \\ OREGON STATE UNIVERSITY \\ UNIVERSITY OF OREGON \\ OSAKA UNIVERSITY \\ UNIVERSITY OF SOUTHERN CALIFORNIA
}

\author{
STANFORD UNIVERSITY \\ UNIVERSITY OF TOKYO \\ UNIVERSITY OF UTAH \\ WASHINGTON STATE UNIVERSITY \\ UNIVERSITY OF WASHINGTON \\ * * * \\ AMERICAN MATHEMATICAL SOCIETY \\ CHEVRON RESEARCH CORPORATION \\ NAVAL WEAPONS CENTER
}

The Supporting Institutions listed above contribute to the cost of publication of this Journal, but they are not owners or publishers and have no responsibility for its content or policies.

Mathematical papers intended for publication in the Pacific Journal of Mathematics should be in typed form or offset-reproduced, (not dittoed), double spaced with large margins. Underline Greek letters in red, German in green, and script in blue. The first paragraph or two must be capable of being used separately as a synopsis of the entire paper. The editorial "we" must not be used in the synopsis, and items of the bibliography should not be cited there unless absolutely necessary, in which case they must be identified by author and Journal, rather than by item number. Manuscripts, in duplicate if possible, may be sent to any one of the four editors. Please classify according to the scheme of Math. Rev. Index to Vol. 39. All other communications to the editors should be addressed to the managing editor, Richard Arens, University of California, Los Angeles, California, 90024.

50 reprints are provided free for each article; additional copies may be obtained at cost in multiples of 50 .

The Pacific Journal of Mathematics is published monthly. Effective with Volume 16 the price per volume (3 numbers) is $\$ 8.00$; single issues, $\$ 3.00$. Special price for current issues to individual faculty members of supporting institutions and to individual members of the American Mathematical Society: $\$ 4.00$ per volume; single issues $\$ 1.50$. Back numbers are available.

Subscriptions, orders for back numbers, and changes of address should be sent to Pacific Journal of Mathematics, 103 Highland Boulevard, Berkeley, California, 94708.

PUBLISHED BY PACIFIC JOURNAL OF MATHEMATICS, A NON-PROFIT CORPORATION

Printed at Kokusai Bunken Insatsusha (International Academic Printing Co., Ltd.), 7-17, Fujimi 2-chome, Chiyoda-ku, Tokyo, Japan. 


\section{Pacific Journal of Mathematics}

\section{Vol. 37, No. $2 \quad$ February, 1971}

Charles Compton Alexander, Semi-developable spaces and quotient images of metric spaces .................................... 277

Ram Prakash Bambah and Alan C. Woods, On a problem of Danzer. . . . . . . . . 295

John A. Beekman and Ralph A. Kallman, Gaussian Markov expectations and related integral equations . ....................................

Frank Michael Cholewinski and Deborah Tepper Haimo, Inversion of the Hankel

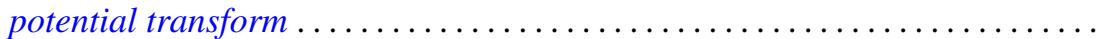

John H. E. Cohn, The diophantine equation

$$
Y(Y+1)(Y+2)(Y+3)=2 X(X+1)(X+2)(X+3) \ldots \ldots \ldots \ldots \ldots
$$

Philip C. Curtis, Jr. and Henrik Stetkaer, A factorization theorem for analytic

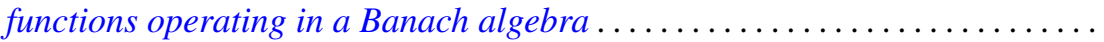

Doyle Otis Cutler and Paul F. Dubois, Generalized final rank for arbitrary limit ordinals

Keith A. Ekblaw, The functions of bounded index as a subspace of a space of entire functions

Dennis Michael Girard, The asymptotic behavior of norms of powers of

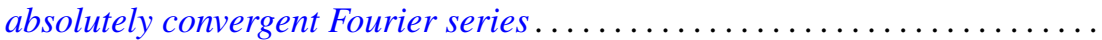

John Gregory, An approximation theory for elliptic quadratic forms on Hilbert spaces: Application to the eigenvalue problem for compact quadratic forms. 383

Paul C. Kainen, Universal coefficient theorems for generalized homology and stable cohomotopy.

Aldo Joram Lazar and James Ronald Retherford, Nuclear spaces, Schauder bases, and Choquet simplexes.

David Lowell Lovelady, Algebraic structure for a set of nonlinear integral operations

John McDonald, Compact convex sets with the equal support property . 429

Forrest Miller, Quasivector topologies

Marion Edward Moore and Arthur Steger, Some results on completability in commutative rings.

A. P. Morse, Taylor's theorem

Richard E. Phillips, Derek J. S. Robinson and James Edward Roseblade, Maximal subgroups and chief factors of certain generalized soluble groups.

Doron Ravdin, On extensions of homeomorphisms to homeomorphisms ...

John William Rosenthal, Relations not determining the structure of $\mathrm{L}$

Prem Lal Sharma, Proximity bases and subbases ........... .

Larry Smith, On ideals in $\Omega_{*}^{u}$. .

Warren R. Wogen, von Neumann algebras generated by operators similar to normal operators

R. Grant Woods, Co-absolutes of remainders of Stone-Čech 